This document is published in:

Scandinavian Journal of Economics (2005), 107(4), 651-672. DOI: 10.1111/j.1467-9442.2005.00431.x

(C) 2005 The editors of the Scandinavian Journal of Economics 


\title{
Panel-data Estimates of the Production Function and the Revenue Function: What Difference Does It Make?*
}

\author{
Jacques Mairesse \\ École Nationale de la Statistique et de l'Administration Économique, F-92245 Malakoff Cedex, France \\ mairesse@ensae.fr
}

Jordi Jaumandreu

Universidad Carlos III, ES-28903 Getafe-Madrid, Spain

jordij@eco.uc3m.es

\begin{abstract}
The lack of individual firm information on output prices is a major problem in the econometrics of production. In particular, it may be expected to account for a significant share of the large discrepancies found between the cross-sectional and time-series estimates of capital and scale elasticities. However, taking advantage of two panel-data samples for which we had such information, we find that estimating the revenue function (using a nominal output measure) or the production function proper (using a real output measure) makes very little difference for our results. The biases due to other sources of specification errors are probably more important.
\end{abstract}

Keywords: Production function; revenue function; panel data; estimation bias; specification errors; price dispersion; capacity utilization

JEL classification: $C 23 ; D 24$

"We have not succeeded in answering all our problems. The answers we have found only serve to raise a whole set of new questions. In some ways we feel we are as confused as ever, but we believe we are confused on a higher level and about more important things." [Quoted in Øksendal (1985) — one of Tor Jakob Klette's favorite quotes]

\section{Introduction}

The lack or unavailability of individual data on firms' output price indices is one of the major problems in the microeconometric analysis of firms'

\footnotetext{
* Mairesse was inspired to write this paper following long and friendly discussions with Zvi Griliches and Tor Jakob Klette. We are particularly grateful to Rozenn Desplatz, Alberto Lopez and Benoît Mulkay for their helpful contributions to the construction and exploratory investigation of the samples, as well as to Bruno Crépon and Patrick Sevestre for remarks and suggestions. An account of preliminary results on the French sample has been published in French in Mairesse and Desplatz (2003).
} 
behavior, obviously as regards not only price-setting behavior but also production, cost and factor demand functions. In the estimation of the production function - the focus of our attention here - the standard practice is to deflate the nominal output of the firm (or its value added) by replacing the unknown individual price index with the price index for the firm industry. This is an imperfect solution, even when output price indices are available at a very detailed level of industry classification. Following Marschak and Andrews (1944) in their innovative analysis of identification issues in estimating production functions, Klette and Griliches (1996) make the point that such an approach cannot prevent biases when the changes in firm prices within industries (even narrowly defined) are substantially dispersed and correlated with the changes in labor and capital (and other production factors). In particular, Klette and Griliches suggest that these biases could be one of the reasons for the observed disparities between the different types of estimates of labor and capital elasticities when using firmpanel data. Our paper seeks to determine whether these propositions are true, while keeping in mind that other sources of bias are also potentially very important.

To what extent does the absence of individual output prices explain why the panel-data estimates which only or mainly rely on the time changes of the variables (i.e., on the longitudinal or "time-series" dimension of the data) are often fairly implausible, leading among other things to very low capital elasticities and rather sharply diminishing returns to scale? To put it differently, can we relate the fact that the panel-data estimates relying mostly on the individual differences in the levels of the variables (the "crosssectional" dimension of the data) are generally more reasonable, to the fact that these estimates are not estimates of the production function stricto sensu, but estimates of the "revenue function" that do not require knowledge of output prices? Can information on firm output prices thus narrow the discrepancies between these two major types of panel-data estimates?

We seek to answer these questions by directly examining the evidence, taking advantage of the fact that we were able to obtain information on firm output price indices for two panel-data samples: a balanced sample for 468 French manufacturing firms over the period 1994-1997, and an unbalanced sample for 675 Spanish manufacturing firms over the period 1991-1999. ${ }^{1}$

\footnotetext{
${ }^{1}$ Until now, Abbott (1991) is the only study, to our knowledge, that has tried to perform a very similar investigation. It relied, however, on a very small sample of only 40 U.S. establishments in the Portland cement industry, for which the author was able to compute average output prices using direct data on the quantities of the different varieties of Portland cement they produced and on the corresponding shipments, available in the 1972, 1977 and 1981 U.S. Census of Manufacturing. As these prices were available only for three years, however, the author was unable to produce estimates based on first differences, as we do, but only estimates based on five- and ten-year differences, reported in Abbot (1987, Chs. 7 and 8).
} 
In our investigation, we were also able to take advantage of information on firm capacity utilization rates, and not only on firm output prices. Indeed, information on capacity utilization is usually lacking in studies on firm panel data. Ignoring changes in firm capacity utilization rates (as well as the correlated changes in the firm's average number of hours worked per employee) is viewed as another serious source of bias in time-series-type estimates, and as a reason for their divergence from cross-sectional-type estimates. The two sources of bias, the lack of data on prices and on capacity utilization at the firm level, are fairly similar, although they reflect different kinds of economic behavior. ${ }^{2}$ In order to assess the specific impact of the dispersion of output price changes on production function estimates, and not to confound it with the impact of the variability in capacity utilization, we chose to take capacity utilization directly into account in most of the estimates reported here.

In the same spirit, we carried out broad experiments in an attempt to take into account the three general sources of potential biases in panel-data estimates: heterogeneity, endogeneity and (random) errors in variables. We relied directly on output price information to assess the related biases, even if this information is far from perfect. This is a more satisfactory approach than trying to indirectly control for heterogeneity, endogeneity and errors in variables. In order to do the latter, we had to rely on instrumental variables (IV) estimation methods and, more specifically, on the generalized method of moments (GMM) applied to panel data. These methods are based on different sets of exogeneity hypotheses (or "orthogonality conditions") that usually produce estimates which are very vulnerable to other types of specification errors, and very imprecise on samples of moderate size such as ours.

In our study, we thus basically compare various sets of estimates of a simple Cobb-Douglas production (or revenue) function in which we do not deflate output (or deflate it only by an industry output price index in keeping with standard practice) and in which we deflate output by our firm output price variable (or include it as an additional control variable in the production function). We begin by looking at the ordinary least squares (OLS) traditional panel-data estimates, and then proceed by considering various panel-data IV estimates with internal and/or external instrumental variables.

Our results do not corroborate initial expectations. Whatever our estimation methods, the introduction of individual output prices into the production function does not in general markedly modify the capital, labor and scale

\footnotetext{
${ }^{2}$ They are two important causes of mismeasurement in firm productivity changes, corresponding to the omission of two critical, but essentially time-varying, variables in the firm production function. Therefore, both are very likely to affect the estimates of factor elasticities, but mostly so in the time-series dimension of the data.
} 
elasticity estimates. Thus, estimating a revenue function instead of a proper production function does not seem to be a major cause of divergence between cross-sectional and time-series estimates of the production function. ${ }^{3}$ It is likely that the main culprits for such divergence remain errors in variables and other types of complex specification errors, which are not well taken into account by the IV (or GMM) panel-data estimators and tend to be exacerbated in the time-series dimension of the data, generating larger biases in that dimension than in the cross-sectional dimension. ${ }^{4,5}$

In Section II of the paper, we follow Klette and Griliches (1996) to illustrate the risks of biases due to the absence of information on firm output prices when estimating the production function. ${ }^{6}$ In Section III, we document and discuss the results obtained for the two samples of French and Spanish manufacturing firms. We briefly conclude in Section IV.

\section{Implications of the Absence of Individual Output Prices}

The effects of the absence of individual output prices on production function estimates are not difficult to analyze if we assume that firms operate in imperfectly competitive markets where actual price differences reflect the differentiation of their products. For simplicity, let us assume that the production function of firm $i$ in year $t$ is a Cobb-Douglas function which can be written in the form of the standard $(\log )$ linear regression:

$$
q_{i t}=a_{t}+\alpha k_{i t}+\beta l_{i t}+u_{i t} \quad \text { with } i=1, \ldots, N \text { and } t=1, \ldots, T,
$$

\footnotetext{
${ }^{3}$ Note that this conclusion was not reached by Abbott (1991). Although he could not effectively regress on first differences using the data available to him (cf. footnote 1), he makes the case that if he had been able to make such regressions they would probably have produced results comparable to the cross-sectional estimates. His argument does not seem very strong, and his estimates in Abbott (1987), based on five- and ten-year differences, are very similar to ours, thereby weakening his conjecture.

${ }^{4}$ On these points, see in particular Mairesse (1990) and Griliches and Mairesse (1998).

${ }^{5}$ Recently, Ornaghi (2005) used a sample from the same Spanish survey data as ours to also address the question of the likely differences in parameter estimates of the production function when using industry or firm output price deflators. He compares GMM estimates on differenced equations, both for gross output and value added, and obtains a marginal improvement in the estimated elasticity of scale when individual price indices are used. However, the elasticity of capital is very small in all his estimates. These results, when placed in a broader perspective, do not contradict our findings, although the author seems more optimistic than we are in interpreting them.

${ }^{6}$ See also Griliches and Mairesse $(1984,1998)$. Melitz (2000) uses basically the same framework as Klette and Griliches (1996), with similar conclusions on the likely biases in estimating the production function when there is lack of information on individual firm output prices. His emphasis, however, is on the proper measurement of total factor productivity at the firm level, not the estimation of the production function parameters.
} 
where $q, k$ and $l$ are, respectively, the logs of volumes of output (measured by value added), capital and labor; $u$ denotes the error or disturbance term, and $a_{t}$ the (log) autonomous technical-progress coefficients (or log average total factor productivity); and $\alpha, \beta$ and $\mu=\alpha+\beta$ are the capital, labor and scale elasticities of interest.

An underlying assumption in this formulation is that we effectively use a real or volume measure of output at the individual firm level. As we usually lack firm information on the prices of output, the volume of the firm output is unknown and usually proxied by the nominal output deflated by an output price index of the firm industry. Instead of $q_{i t}=\left(y_{i t}-p_{i t}\right)$, we therefore measure $\left(y_{i t}-p_{S t}\right)$, where $y_{i t}$ is nominal $(\log )$ output, and $p_{i t}$ and $p_{S t}$ are, respectively, the $(\log )$ price index of firm $i$ and the $(\log )$ price index of industry $S$ (to which firm $i$ belongs). While we should estimate equation (1), the equation we usually estimate is in fact:

$$
\left(y_{i t}-p_{S t}\right)=q_{i t}+\left(p_{i t}-p_{S t}\right)=a_{t}+\alpha k_{i t}+\beta l_{i t}+f_{i t},
$$

where the firm $(\log )$ price deviation from the industry $(\log )$ price (i.e. the $\log$ of the firm price relative to the industry price) is embedded in the disturbance term:

$$
f_{i t}=\left(p_{i t}-p_{S t}\right)+u_{i t} .
$$

It is thus fairly obvious that the estimates of capital, labor and scale elasticities $\alpha, \beta$ and $\mu=\alpha+\beta$, will be biased if the firm output prices are (i) significantly dispersed within industry and (ii) significantly correlated within industry with the production factors. This bias problem is a priori hard to address by means of an instrumental-variables estimation method. Indeed, finding valid instruments seems particularly difficult, as any variable correlated with labor and capital (and the other production factors) will probably be correlated with the output prices as well, via the firm's production function and demand function.

More precisely, let us suppose that the firm's demand function results from the imperfect substitutability of its products with those of competing firms in the same industry and that it can be written simply in the form of a $(\log )$ linear regression:

$$
\left(q_{i t}-q_{S t}\right)=\eta\left(p_{i t}-p_{S t}\right)+w_{i t},
$$

where $\left(q_{i t}-q_{S t}\right)$ is the $(\log )$ share of the firm real output in that of the industry, $\left(p_{i t}-p_{S t}\right)$ the $(\log )$ of the firm price relative to that of the industry, and $\eta$ the price elasticity of demand, which is, in principle, negative $(\eta<0)$. This function implies that the firm, owing to product differentiation, can capture an additional share of the industry market by lowering its price. A $1 \%$ reduction in its relative price $\left(p_{i t}-p_{S t}\right)$ will boost its market share 
$\left(q_{i t}-q_{S t}\right)$ by $-\eta \%$, other things equal. The term $w_{i t}$ denotes the other demand determinants and shifters, and the various demand shocks that may influence demand for the firm's products, independent of price changes; they include investments in research and product innovation, advertising and marketing expenditures, changes in consumer income and tastes, and so on.

The inverse demand function, expressing relative price as a function of the demand shocks and the firm market share in real or value terms $\left(q_{i t}-q_{S t}\right)$ or $\left(y_{i t}-y_{S t}\right)=\left(q_{i t}-q_{S t}\right)+\left(p_{i t}-p_{S t}\right)$, can be written equivalently as:

$$
p_{i t}-p_{S t}=\eta^{-1}\left(q_{i t}-q_{S t}-w_{i t}\right)=(1+\eta)^{-1}\left(y_{i t}-y_{S t}-w_{i t}\right) .
$$

Through substitution in the estimated production function, we can then formulate it as:

$$
\left(y_{i t}-p_{S t}\right)=\omega^{-1}\left(a_{t}+\alpha k_{i t}+\beta l_{i t}\right)+\epsilon_{i t},
$$

where $\epsilon_{i t}=\left(\eta^{-1} q_{S t}+\omega^{-1} u_{i t}+\eta^{-1} w_{i t}\right)$ and $\omega=\eta /(1+\eta)$ is the markup ratio (or market power parameter). This new expression of the production function, as estimated in practice as a revenue function (in output-value terms or in value terms deflated by an industry price index), gives us an idea of the potential size of the biases that may influence the factor-elasticity estimates. $^{7}$ It suggests that the revenue function estimates of labor, capital and scale elasticities could be downward-biased relative to the production-function estimates proper. Such underestimation would be inversely proportional to the markup $\omega$, and thus larger for a smaller absolute price elasticity of demand; it could, for example, be about $30 \%$ for a price elasticity $\eta$ on the order of -4 and a markup $\omega$ on the order of $1.30{ }^{8}$

These conclusions do not apply, of course, unless the analytical framework that we have just described is suitable, and especially unless the hypothesis of a firm demand function as specified above is satisfactory. We need to make three important observations in this respect, regarding three cases where the correlation between output prices and production factors would be negligible, and hence the ensuing biases as well.

\footnotetext{
${ }^{7}$ It also shows that the disturbance term $\epsilon$ is affected by both supply shocks $u$ and demand shocks $w$; hence only variables impervious to both types of shocks can serve as valid instruments for the production function in output value terms. We also note that if we explicitly introduce the industry-output variable $q_{S t}$ into this production function, it becomes possible, in theory, to identify and estimate the demand-elasticity parameter $\eta$, and therefore the markup parameter $\omega$; from that, we can infer unbiased estimates of capital elasticity $\alpha$ and labor elasticity $\beta$, even lacking information on individual prices. That is in fact the solution suggested by Klette and Griliches (1996) and also implemented, for example, in Crépon, Desplatz and Mairesse (1999).

${ }^{8}$ These orders of magnitude are those preferred by Crépon et al. (1999) for a sample of French manufacturing firms comparable to the French sample used here.
} 
The first observation concerns the case of (near) perfect competition where the price elasticity of demand tends toward a very high value, and the markup ratio toward unity. Here, the biases would be negligible and the "between-firms" dispersion of changes in actual individual prices would essentially reflect (random) measurement errors. This situation does not seem very realistic, however, except in some highly competitive industries and perhaps over the long run.

The second observation concerns the case where the relation between the changes in real output and the changes in output prices, as expressed by the firm demand function (estimated in the time dimension of the data), is weak relative to that between the demand shocks and the other determinants of demand (the changes in $w_{i t}$ ). In this case, the simple correlation (unconditional on the other demand determinants) between output prices and output volumes will be small, and hence also the transmitted correlation between output prices and the production factors. The latter will therefore be fairly unimportant compared to the correlations between the errors in the production function $u_{i t}$ and the production factors, due to other likely specification errors. This is the more plausible reason why our panel-data estimates actually display little change - as we will observe-when we are able to take into account the individual output price information.

The third observation is particularly important in the context of panel data, since it provides a justification for estimating the production function or revenue function from the levels of the variables and not only from their changes (or log first differences), irrespective of whether output is expressed in value or volume terms. In the levels of the variables, estimation of a production function in terms of "physical quantities" (or some other natural units) is in fact meaningless - unless we confine the analysis to a very precisely defined industry where the goods are so homogeneous that firm outputs can be well measured and compared across firms in this way. ${ }^{9}$ In the general case where the goods produced are heterogeneous, we can only expect to find meaningful estimates of the production function or revenue function, when firm outputs are measured in units of "volume" (say in euros) at the prices of the goods for a given base year, or in units of "value" (say in euros) at the prices of the different goods in the current year. However, the price differences across firms will, by construction, be zeros in the chosen base year, and it is plausible that the correlations across firms, in any other year, between price differences and real output differences will remain small for reasons similar to those suggested above (idiosyncratic demand shocks and other firm-specific determinants will be likely to prevail). Altogether it should not come as a

\footnotetext{
${ }^{9}$ This criticism dates back to the first studies by Douglas on estimating the (Cobb-Douglas) production function on cross-sectional firm data instead of aggregate series as before. It has since been vigorously reiterated, notably by Phelps-Brown (1957).
} 
surprise that estimating the production or the revenue function (i.e., whether output is deflated by individual prices or not) makes little difference for the results when they rely mainly on a cross-sectional dimension and do not control adequately for individual firm-correlated effects.

\section{Estimating a Production Function with and without Individual Output Prices}

\section{Samples, Variables, Model Specifications and Estimators}

Our samples consist of a balanced panel of 468 French firms for the four-year period 1994-1997, and an unbalanced panel sample of 675 Spanish firms for the nine-year period 1991-1999. Details on the origin and construction of the samples and on the exact definitions of the variables can be found in the working paper version of this article. ${ }^{10}$ The main feature of the two samples is the availability at the firm level of information on output price changes, as well as on the rates of capacity utilization. Basically, what we do is systematically compare a large variety of estimates of the simple Cobb-Douglas production function, generally including the firm rate of capacity utilization as a RHS variable, and using the firm value added undeflated $\left(y_{i t}\right)$, deflated by an industry output-price index $\left(y_{i t}-p_{S t}\right)$ and deflated by the firm output-price index $\left(y_{i t}-p_{i t}\right)$, respectively, as the dependent variable. We also experiment by including the firm output-price index as a RHS variable (with value added undeflated as the dependent variable).

Precisely, we estimate linear regressions of the following form:

$$
\left(y_{i t}^{*}-l_{i t}\right)=a_{t}+\alpha\left(k_{i t}-l_{i t}\right)+(\mu-1) l_{i t}+\delta u c_{i t}+\gamma p_{i t}^{*}+u_{i t},
$$

where $\left(y_{i t}^{*}-l_{i t}\right)$ is the log of firm labor productivity measured as value added per worker - undeflated or deflated as specified in each case; $\left(k_{i t}-l_{i t}\right)$ the log of physical capital per worker at the beginning of the year, measured by the gross book value in the firm balance sheet (adjusted for inflation); $l_{i t}$ the log of labor expressed as the number of employees; $u c_{i t}$ the log of the rate of utilization of capacity as declared by the firm; $p_{i t}^{*}$, as specified in each case, either the log of the industry price index (available from the national accounts) or the firm price index as declared by the firm.

\footnotetext{
${ }^{10}$ Our samples consist mainly of medium-sized firms in the two countries with a mean size of 275 and 198 employees in the case of France and Spain, respectively. Although the proportion of largest firms is not so different in the two samples (the 20th percentiles are 869 and 739 employees in the case of France and Spain, respectively), the Spanish sample has relatively more small firms, which agrees with the overall size distributions of manufacturing firms in the two countries. The working paper version is available on request.
} 
The year coefficients $a_{t}$ account for technical change (and other general effects of time on productivity, such as those arising from the general business cycle, and not captured by firm capacity utilization rates); $\alpha, \beta=(\mu-\alpha)$ and $\mu$ are, respectively, the capital, labor and scale elasticity parameters. In general, we assume - as is usual in panel-data econometrics - that the disturbance term $u_{i t}$ can be decomposed into two error components $u_{i t}=u_{i}+v_{i t}$, where $u_{i}$ represents an individual firm effect, supposedly invariant over time, and $v_{i t}$ is the idiosyncratic firm and time-specific disturbance, supposedly uncorrelated across firms and over time. We also consider, however, the possibility that $v_{i t}$ is a first-order serially correlated error term of the form $v_{i t}=\rho v_{i t-1}+e_{i t}$ (with $e_{i t}$ uncorrelated across firms and over time).

We systematically examine the results of the following six regressions: (1) a "revenue" function ( $y_{i t}^{*}=y_{i t}$ and $\delta=\gamma=0$ ); (2) a revenue function controlling for capacity utilization $\left(y_{i t}^{*}=y_{i t}\right.$ and $\left.\gamma=0\right)$; (3) a production function using the industry output price $p_{S t}$ for deflation $\left(y_{i t}^{*}=y_{i t}-p_{S t}\right.$ and $\gamma=0)$; (4) a production function using the firm output price $p_{i t}$ for deflation $\left(y_{i t}^{*}=y_{i t}-p_{i t}\right.$ and $\left.\gamma=0\right)$; (5) the inclusion of $p_{S t}$ as a RHS variable $\left(y_{i t}^{*}=y_{i t}\right.$ and $\left.p_{i t}^{*}=p_{S t}\right)$; and (6) the inclusion of $p_{i t}$ as a RHS variable $\left(y_{i t}^{*}=y_{i t} \text { and } p_{i t}^{*}=p_{i t}\right)^{.1}$

Panel-data estimators of these types of regressions are aimed at addressing three main possible causes of bias: (i) the presence of individual heterogeneity (or unobserved firm effects), embodied in the $u_{i}$ component of the disturbance term, possibly correlated with all or part of the explanatory variables; (ii) the likely endogeneity of some variables due to their simultaneous determination, or their potential correlation with the past and contemporaneous component $v_{i t}$ of the disturbance; and (iii) the presence of errors in variables, which raises another source of correlation with the disturbance. We consider two types of estimators which try to control for some of the sources of bias. ${ }^{12}$ We begin with the traditional OLS estimators in levels and first differences. First differences control for individual heterogeneity simply by removing the firm effects $u_{i}$ from the equation. We then experiment with a series of IV or GMM panel-data estimators, which endeavor to correct for the other two sources of potential bias by using appropriate instruments: basically the lagged variables in levels if the production function equations are in first differences, and the lagged variables in first differences if the production function equations are in levels. For the Spanish sample, we are also able to use two external instruments: the average wage and an index of the prices of intermediate consumption. This sample is also

\footnotetext{
${ }^{11}$ Actually, except for the OLS estimates (in Table 2), for the IV estimates (in Tables 3 to 5) we include $p_{i t}$ instead of $p_{S t}$ in (5) as in (6), but we treat it as an exogenous variable in (5), and as a variable contemporaneously correlated with the error in (6).

${ }^{12}$ Up-to-date reviews of panel-data estimators can be found, for example, in Arellano and Honore (2001) and Arellano (2003).
} 
large enough to allow us to investigate the possibility of a first-order serially correlated idiosyncratic disturbance $v_{i t}$ by instrumenting the production function written in terms of quasi-differences by the lagged variables in first differences.

Table 1 reports some simple descriptive statistics concerning means, dispersion and correlations among the variables. Table 2 reports the OLS estimates, Table 3 the basic IV estimates, Table 4 the IV estimates in quasidifferences and Table 5 the estimates using external instruments.

\section{Descriptive Statistics}

Let us comment on Table 1. The average growth rates of value added, the number of employees, physical capital stock and the degree of capacity utilization are higher in the Spanish sample than in the French sample, which is in accordance with the good overall performance of the Spanish economy in the 1990s. The average growth rates of firm output prices are also faster in the Spanish sample $(2.2 \%)$ than in the French sample $(0.3 \%)$. They are both roughly consistent with the corresponding industry output prices from national accounts. As anticipated, however, the growth rates in output prices are significantly more dispersed at the firm level than at the industry level.

The pattern of correlations is on the whole similar in both samples, and concurs well with what could be expected. Changes in value added are positively and significantly correlated with the changes in labor, capital and capacity utilization. Changes in capital are also positively correlated with those in labor (and negatively with capacity utilization in the French sample). Also as expected, firm output price changes are positively and significantly correlated with industry price changes, although more strongly so in the French sample than in the Spanish sample.

More interestingly, firm output price changes are also positively and significantly correlated with the changes in capacity utilization in both samples. This is a nice confirmation of the informative content of the variables, because firms are likely to raise prices as capacity is increasingly used and marginal cost rises. Moreover, firm price changes are also positively correlated with value-added changes. No particular sign is expected for this simple (overall) correlation, since changes in nominal value added can be positively related to price changes. This is due to the effects of other demand factors $w_{i t}$ (and of being undeflated), even though they are negatively related to these price changes, conditional on the other factors through the firm demand relationship (with $(\eta<-1)$ ).

\section{OLS Panel-data Estimates}

Table 2 displays the OLS panel-data estimates in the "levels" of the variables (which treat the cross-sectional and time-series dimensions of the data 
Table 1. Means, standard deviations and correlations of the main variables in growth rates (log first differences)

\begin{tabular}{lccclll}
\hline & DLVA & DLL & DLK & DLCU & DLPI & DLPF \\
\hline Panel A: France & & & & & & \\
Mean (in \%) & 1.8 & 0.1 & 1.6 & 0.2 & 0.4 & 0.3 \\
Standard deviation (in \%) & 18.3 & 8.6 & 8.3 & 6.4 & 2.5 & 3.5 \\
Correlations & & & & & & \\
$\quad$ Value-added DLVA & 1 & & & & & \\
$\quad$ Number of employees DLL & $0.22^{* * *}$ & 1 & & & & \\
$\quad$ Physical capital stock DLK & $0.05^{*}$ & $0.05^{*}$ & 1 & & & \\
$\quad$ Capacity utilization DLCU & $0.09^{* * *}$ & 0.04 & $-0.09^{* * *}$ & 1 & & \\
$\quad$ Industry price DLPI & $0.09^{* * *}$ & $0.08^{* * *}$ & $-0.05^{* *}$ & $0.05^{*}$ & 1 & \\
$\quad$ Firm price DLPF & $0.13^{* * *}$ & $0.10^{* * *}$ & 0.01 & $0.07^{* *}$ & $0.28^{* * *}$ & 1 \\
Panel B: Spain & & & & & & \\
Mean (in \%) & 4.2 & 0.4 & 5.6 & 0.5 & 2.2 & 1.3 \\
Standard deviation (in \%) & 26.0 & 12.2 & 18.4 & 13.6 & 3.6 & 5.2 \\
Correlations & & & & & & \\
$\quad$ Value-added DLVA & 1 & & & & & \\
$\quad$ Number of employees DLL & $0.29^{* * *}$ & 1 & & & & \\
$\quad$ Physical capital stock DLK & $0.07^{* * *}$ & $0.12^{* * *}$ & 1 & & & \\
$\quad$ Capacity utilization DLCU & $0.09^{* *}$ & $0.04^{* *}$ & -0.00 & 1 & & \\
$\quad$ Industry price DLPI & -0.01 & $-0.04^{* *}$ & 0.01 & 0.01 & 1 & \\
$\quad$ Firm price DLPF & $0.08^{* * *}$ & 0.02 & -0.02 & $0.05^{* * *}$ & $0.09^{* * *}$ & 1 \\
\hline
\end{tabular}

Notes: For France: balanced sample 1995-1997, 468 firms, 1,404 observations. For Spain: unbalanced sample 1992-1999, 675 firms, 3,628 observations. The asterisks ***, ** and * indicate that the correlations are statistically significant at a confidence level of $1 \%, 5 \%$ and $10 \%$, respectively. DLVA, DLL, DLK, DLCU, DLPI and DLPF are, respectively, the log first differences of firm value-added (undeflated), of firm average number of employees, of firm physical stock of capital (at the beginning of the year), of firm degree of capacity utilization, of industry output price (from the national accounts) and of firm output price.

in the same way), and in the (log) "first differences" of the variables (which rely only on the time-series dimension of the data by removing its crosssectional dimension). In both levels and first differences, the estimated elasticities of capital and scale, and hence of labor, are quite close in the French and Spanish samples: about $0.20-0.25,1.05-1.10$ and $0.80-0.85$, respectively, in levels, and sharply decreasing in first differences to about $0.05-0.10,0.65-0.55$ and $0.50-0.60$, respectively. ${ }^{13}$

${ }^{13}$ While the first-difference transformation of the data takes care of the biases arising from correlated firm effects, it is well known, however, that this transformation exacerbates the importance of the downward biases arising from errors in variables. This is a likely explanation for the large downfall in the production function estimates of the elasticities of capital, labor and scale in first differences; see, for example, Mairesse (1990) and Griliches and Mairesse (1998). 
Table 2. OLS estimates in levels and in first differences

LVAL LVAL LVADIL LVADFL LVAL LVAL

$\begin{array}{llllll}(1) & \text { (2) (3) (4) }\end{array}$

Panel A: France

Levels

LKL

LL

LCU

LPF (or LPI in regression column (5))

$R^{2}$

(m.s.e.)

First differences

LKL

LL

LCU

LPF (or LPI in regression $R^{2}$ column (5)) $R^{2}$

(m.s.e.)

$\begin{array}{cccccc}0.25 & 0.25 & 0.26 & 0.26 & 0.26 & 0.26 \\ (0.02) & (0.02) & (0.02) & (0.02) & (0.02) & (0.02) \\ 0.04 & 0.03 & 0.03 & 0.03 & 0.03 & 0.03 \\ (0.01) & (0.01) & (0.01) & (0.01) & (0.01) & (0.01) \\ - & 0.26 & 0.25 & 0.23 & 0.25 & 0.25 \\ & (0.13) & (0.13) & (0.13) & (0.13) & (0.13) \\ - & - & - & - & 0.58 & 0.23 \\ & & & & (0.26) & (0.14) \\ 0.998 & 0.998 & 0.998 & 0.998 & 0.998 & 0.998 \\ (0.274) & (0.274) & (0.274) & (0.278) & (0.274) & (0.273) \\ & & & & & \\ 0.08 & 0.10 & 0.11 & 0.09 & 0.10 & 0.09 \\ (0.05) & (0.05) & (0.05) & (0.05) & (0.05) & (0.05) \\ -0.46 & -0.45 & -0.45 & -0.49 & -0.45 & -0.47 \\ (0.08) & (0.08) & (0.08) & (0.08) & (0.08) & (0.08) \\ - & 0.27 & 0.26 & 0.24 & 0.27 & 0.25 \\ & (0.09) & (0.09) & (0.09) & (0.09) & (0.09) \\ - & - & - & - & 0.50 & 0.56 \\ & & & & (0.22) & (0.15) \\ 0.074 & 0.083 & 0.085 & 0.087 & 0.087 & 0.093 \\ (0.126) & (0.126) & (0.126) & (0.126) & (0.126) & (0.125)\end{array}$

\section{Panel B: Spain}

Levels

LKL

LL

LCU

LPF (or LPI in regression column (5)) $R^{2}$

(m.s.e.)

First differences

LKL

LL

\section{LCU}

LPF (or LPI in regression column (5)) $R^{2}$

(m.s.e.)

$\begin{array}{cccccc}0.22 & 0.22 & 0.22 & 0.24 & 0.22 & 0.22 \\ (0.02) & (0.02) & (0.02) & (0.02) & (0.02) & (0.02) \\ 0.08 & 0.07 & 0.07 & 0.07 & 0.07 & 0.07 \\ (0.01) & (0.01) & (0.01) & (0.01) & (0.01) & (0.01) \\ - & 0.29 & 0.29 & 0.28 & 0.29 & 0.29 \\ & (0.06) & (0.06) & (0.07) & (0.06) & (0.06) \\ - & - & - & - & -0.26 & 0.05 \\ & & & & (0.18) & (0.09) \\ 0.998 & 0.998 & 0.998 & 0.998 & 0.998 & 0.998 \\ (0.379) & (0.376) & (0.378) & (0.395) & (0.376) & (0.376) \\ 0.06 & 0.06 & 0.06 & 0.06 & 0.06 & 0.06 \\ (0.02) & (0.02) & (0.02) & (0.02) & (0.02) & (0.02) \\ -0.35 & -0.35 & -0.35 & -0.36 & -0.35 & -0.36 \\ (0.04) & (0.04) & (0.04) & (0.04) & (0.04) & (0.04) \\ - & 0.14 & 0.14 & 0.13 & 0.14 & 0.14 \\ & (0.04) & (0.04) & (0.04) & (0.04) & (0.04) \\ - & - & - & - & -0.27 & 0.32 \\ & & & & (0.14) & (0.10) \\ 0.068 & 0.074 & 0.051 & 0.062 & 0.075 & 0.078 \\ (0.175) & (0.174) & (0.176) & (0.176) & (0.174) & (0.174) \\ & & & & & \end{array}$


When included in the regression, capacity utilization enters with a positive and significant coefficient as expected, but almost without bringing about any changes in the other estimated parameters (compare the first and second columns of each panel of Table 2). Interestingly, the estimated coefficient of capacity utilization is in levels about equal to that of capital, and in first differences it does not fall for the French sample, and decreases much less than that of capital for the Spanish sample. The likely reason is, of course, the role that this variable plays in the adjustment of the capital stock of the firm to the unanticipated (or anticipated as transitory) variations of its production. ${ }^{14}$

Using undeflated value added, or deflating it by an industry price index or by an individual firm-price index, has almost no effect on the estimates (compare the second, third and fourth columns of each panel of Table 2). We may simply conclude that, to the extent the conventional OLS panel-data estimators are relevant and we focus on estimating the elasticities of interest, it does not matter whether we consider the revenue function or the production function. The inclusion of the industry and firm price indices as RHS variables does not make more of a difference in the other parameter estimates (compare columns 5 and 6 to the previous ones). Their own coefficients, however, in both the levels and first-differences regressions, tend to be significant, positive and not too different for the French sample, but surprisingly of different signs for the Spanish sample. This is hardly interpretable, because the two price indices cannot be viewed solely as missing deflators, but also as variables which are likely to be correlated with the error term, due to both

Notes for Table 2: For France: balanced sample 468 firms: 1994-1997 and 1995-1997 (1,862 and 1,404 observations) for regressions in levels and in first differences, respectively. For Spain: unbalanced sample 675 firms: 1991-1999 and 1992-1999 (4,403 and 3,628 observations) for regressions in levels and in first differences, respectively. Standard errors of estimated coefficients, robust to heteroskedasticity across individuals and arbitrary correlation over time, are given in parentheses. Year dummy variables are included in all regressions; industry dummy variables are also included in the regressions in levels. All variables are in logarithms. LVAL, LVADIL and LVADFL are, respectively, productivity undeflated, deflated by industry price, and deflated by firm price, where productivity is measured in terms of firm value added per employee. LKL is the physical stock of capital per employee at the beginning of the year, measured by the gross book value in the firm balance sheet (adjusted for inflation); LL is the firm average number of employees; LCU is the firm degree of capacity utilization; LPI is the industry price variable; and LPF is the firm price variable.

${ }^{14}$ To put it differently, the capital stock, as we measured it on the basis of the book value of the firm in the balance sheet, is a better proxy for capital services if adjusted by the changes in capacity utilization. Using, when possible, such an adjusted measure in the production function may to a large extent be more appropriate and can help limit the sharp downfall in the estimates of capital elasticity in first differences as compared with the estimates in levels. 
likely errors in variables and the endogeneity of output prices (through the firm demand equation). ${ }^{15}$

\section{Panel-data Estimates}

Tables 3-5 display the results of applying a number of IV or GMM paneldata estimators. ${ }^{16}$ Let us briefly review what these estimators are, before reporting their results. First, while keeping the production function equation specified in levels, we instrument the endogenous capital and labor variables with their past differences or with the differences of the external instruments (estimates shown in the upper panels in Tables 3 and 5). ${ }^{17}$ The external instruments which we use to instrument the capital and labor variables are the firm-specific average wage and a firm-specific index of the price paid in intermediate consumption (materials, energy and services). Second, by writing the production function equations in first differences to remove the individual firm effects, we instrument the endogenous capital and labor variables with their past levels (lower panels in Table 3 ). ${ }^{18}$ In both cases, we convinced ourselves that it was more appropriate to regard the capacity utilization and output price variables (when included in the production function specification) as only contemporaneously correlated with the disturbance term (resulting from errors in measurement, among other reasons). Consequently, we instrument them using both past and forward values of their levels or differences. In any case, simply using the lagged values as instruments did not result in any noteworthy changes, only less precise estimates. Third, we also experimented with the production function equation specified in quasi-differenced form, which allows for a possibly firstorder serially correlated disturbance $v_{i t}$ in the original equation, using as instruments the endogenous capital and labor variables with their past differences. ${ }^{19}$ Table 4 documents these estimates; the upper panel shows

\footnotetext{
${ }^{15}$ We have also carried out "within-firm" and "long differences" panel-data estimates, which can be found in the working paper version. The "within-firm" estimator refers to OLS performed on the deviations of the variables from their firm means, and the "long differences" estimator refers here to OLS performed on the four-year lagged differences of the variables. While these estimators tend to produce estimates somewhere in between the estimates in levels and first differences, our conclusions are basically unchanged.

${ }^{16}$ The precision of the IV estimates for the French sample suffers from its very short period (four years). Therefore, the results for the French sample are shown only in Table 3 . The estimates for the Spanish sample were also extremely imprecise when we reduced it, for the sake of comparison, to a balanced sample over four years.

${ }^{17}$ Such estimators have been strongly advocated, for example, in Arellano and Bover (1995).

${ }^{18}$ See, for example, Arellano and Bond (1991).

${ }^{19}$ See Blundell and Bond (2000), who also apply this type of estimator to estimation of the production function. We have also estimated other variants of this estimator with similar results or worse.
} 


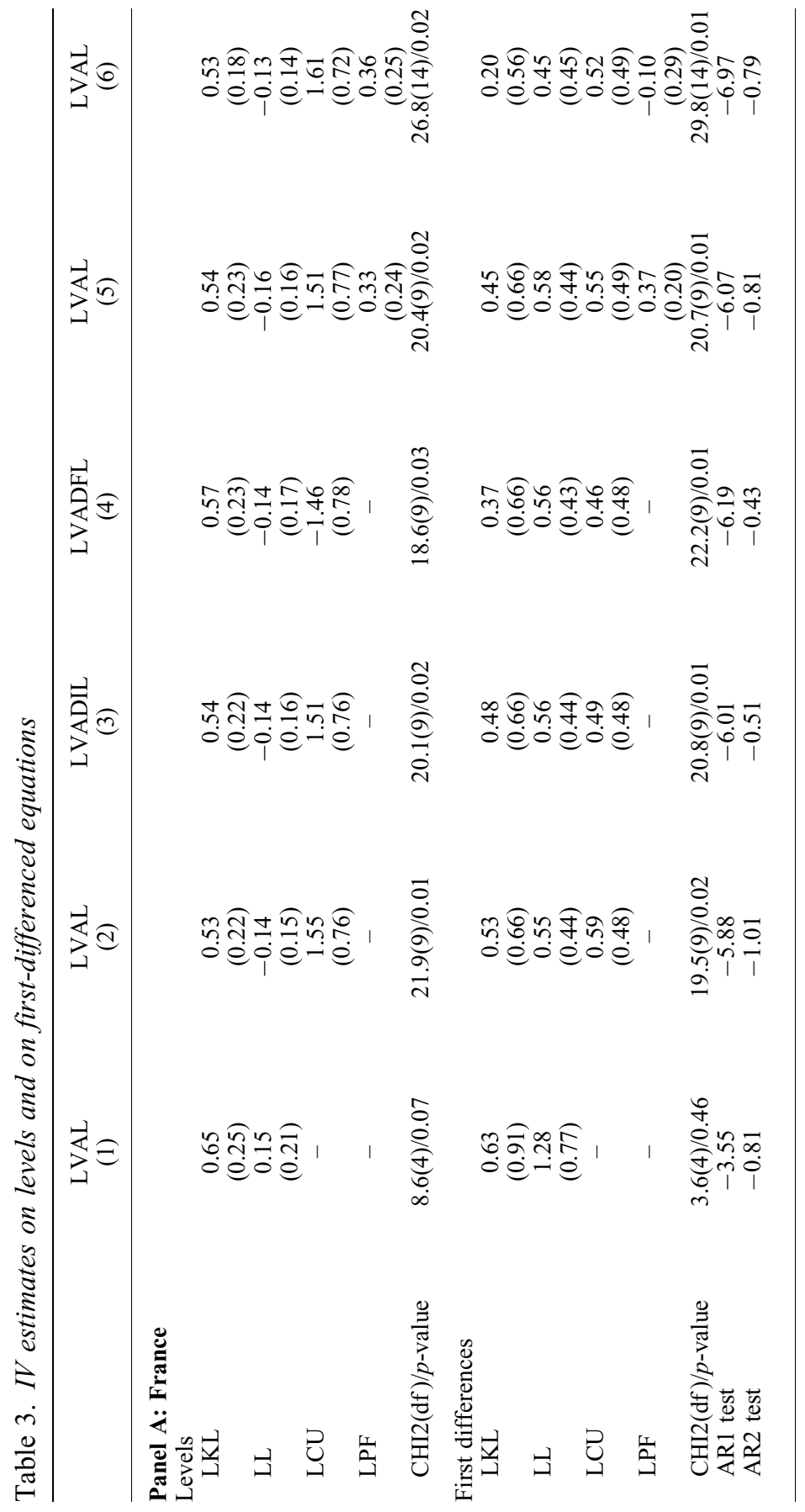




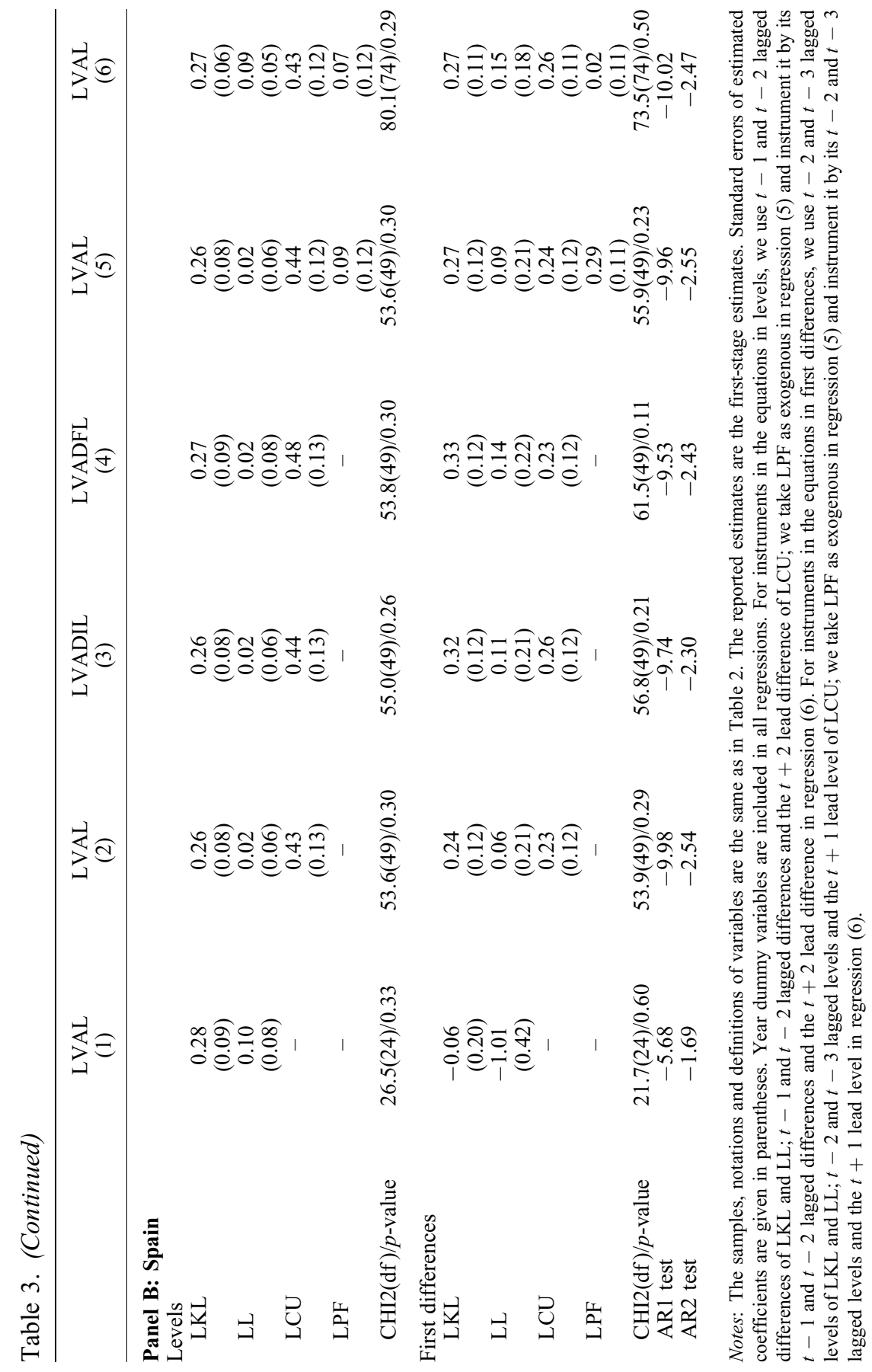




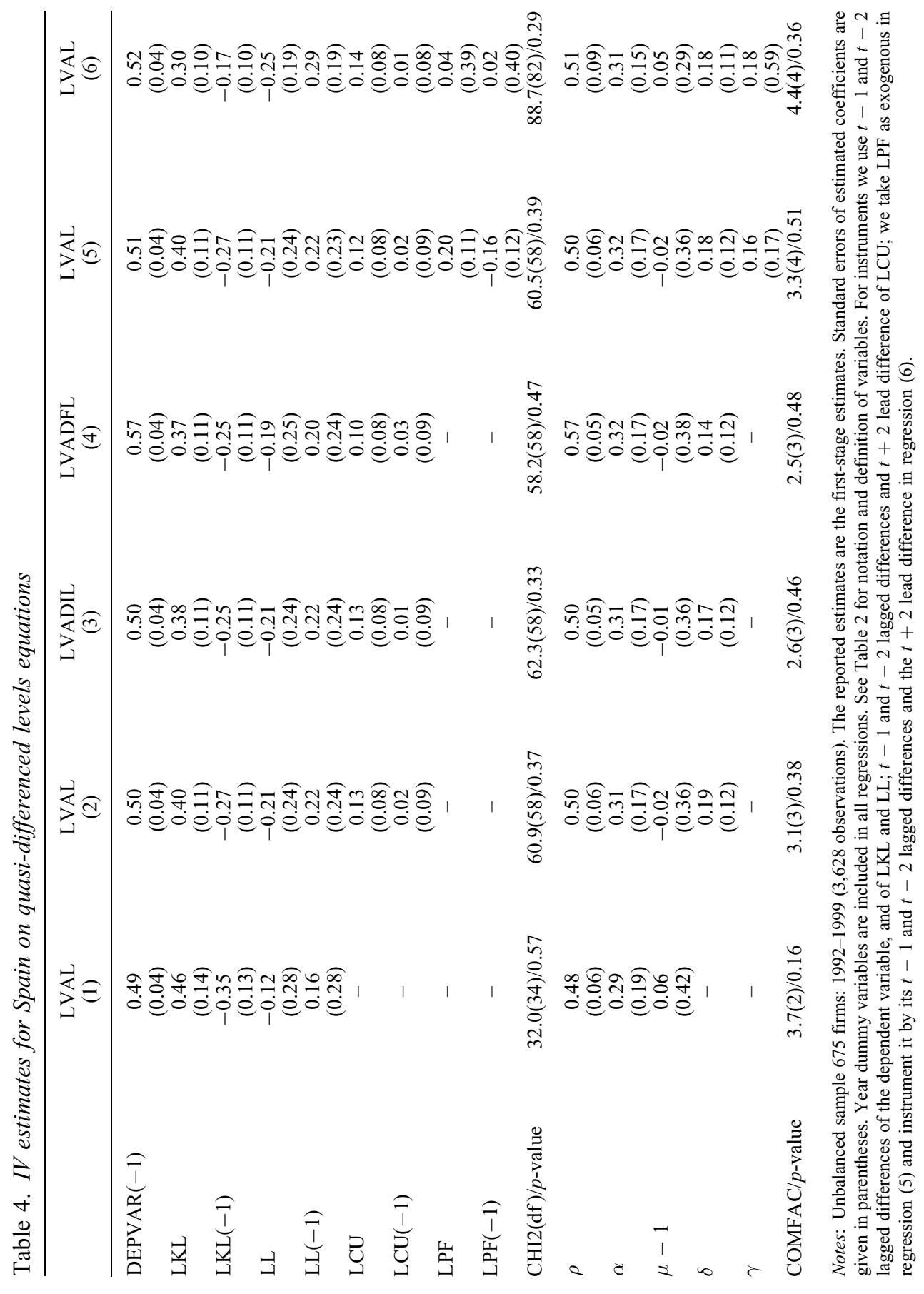




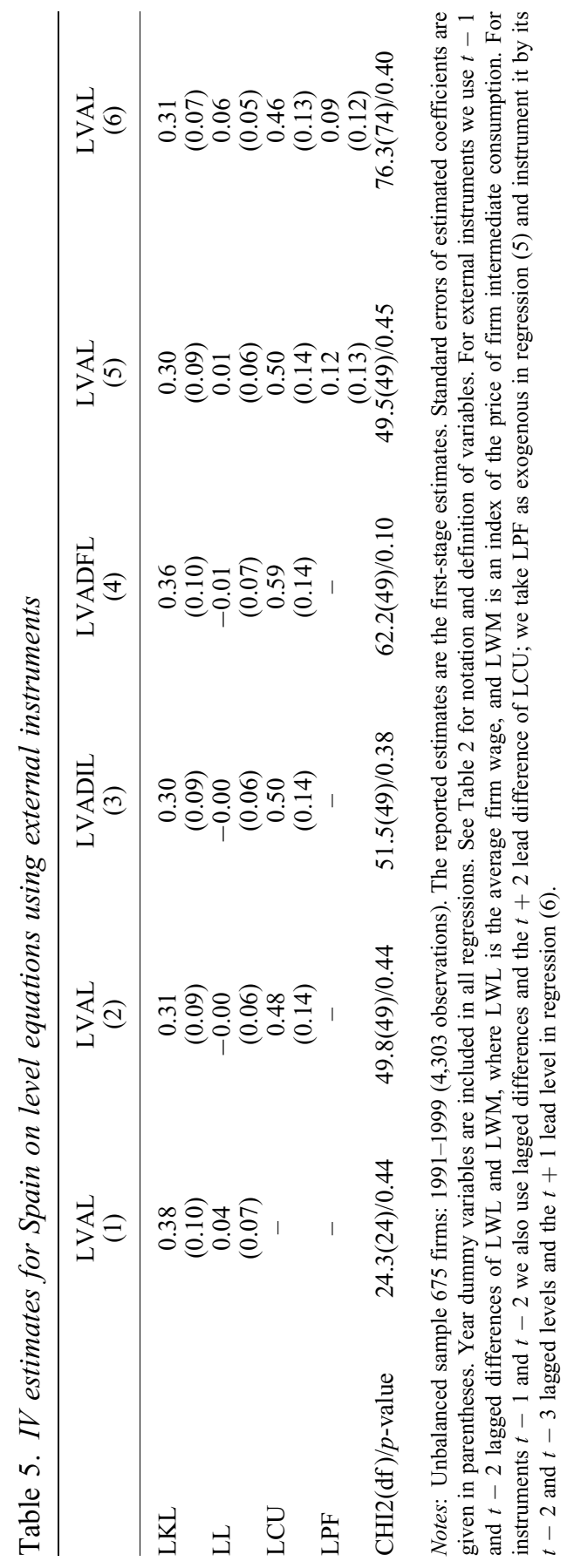


the unconstrained estimates, while the lower panel gives the minimum distance estimates of the underlying parameters derived from them and reports on the chi-square test (or COMFAC test) of the imposed constraints. ${ }^{20}$

The IV estimates of the elasticity of capital generally tend to be higher than the OLS estimates in first differences. Again, however, they tend to vary more with the estimation procedure than with the particular specification of the production function equations. The highest and most significant estimates are in fact obtained when the equations in levels are instrumented with lagged differences of the variables as well as, in the case of the Spanish sample, when instrumenting the levels of the quasi-differenced equations and when using external (differenced) instruments. On the other hand, the IV estimates on the first-differenced equations are extremely imprecise (and practically worthless) in the case of the French sample, and still quite poor, although much less so for the Spanish sample. The problems generated by differencing the equations are actually aggravated by the fact we use only the lagged variables as instruments and by the relatively small size of our samples. ${ }^{21}$

Also in contrast to the OLS estimates in first differences, the hypothesis of constant returns to scale is accepted by all the IV estimates. The best estimates here are, once again, obtained for the Spanish sample when the production function equations in levels are instrumented by the lagged differences of the variables (as well as by the external instruments): the relevant scale parameter $(\mu-1)$ is very close to zero, and relatively precisely estimated.

The other estimates, however, are more imprecise even when the equations are instrumented in levels, and again they appear quite poor when the equations are instrumented in first differences. The coefficient on the capacity utilization variable tends to vary widely, more so than the elasticity of capital, and in ways mainly related to the method of estimation. It can be

${ }^{20}$ All the IV estimators reported here are set in a GMM framework, using (part of) the available moment restrictions at each cross-section. We always constrain the number of instruments, using the closest a priori legitimate lags or leads. The instruments in each case are detailed in the notes to the tables. All estimates reported are first-step estimates, based on the first-step estimator of the weighting matrix, in turn based on the variance-covariance matrix of the instruments. The reported standard errors are robust to heteroskedasticity across firms and arbitrary time correlation. For all specifications, we report the Sargan test of overidentifying restrictions. For the specifications in first differences, we also report the test of first- and second-order autocorrelation of the residual proposed by Arellano and Bond (1991)

${ }^{21}$ The "poor" performances of these first-differenced IV (or GMM) estimators in such cases are neither new nor very surprising. See, for example, the simulations by Crépon and Mairesse (1996) for a sample of comparable size to the French sample $(T=3$ and $N=400)$ and a configuration close to that of the estimation of a production function. 
noted that this variable turns out to be crucial for obtaining at least sensiblelooking, though still imprecise, estimates when instrumenting the equations in first differences for the Spanish sample (lower panel in Table 3). It seems clear that at least capacity utilization plays an important role as a control in the production function.

As in the case of the OLS estimates, using undeflated value added or deflating it by an industry price index or by an individual firm price index has almost no effect on the different IV estimates. Likewise, when included as a RHS variable, output price tends to enter positively and imprecisely, though with a coefficient significantly different from 1 . Our IV results merely confirm our conclusion that it does not matter whether we consider the revenue function or the production function. Nonetheless, the fact that the output price enters positively in the production function but has a negligible impact on the estimated parameters of the other variables, indicates that it is positively correlated with the disturbance term. One way to understand this (apparent) puzzle is to view output price as one endogenous determinant among many others of the firm demand function, which should be analyzed in a more general model of firm behavior. This suggests that the ways in which firm output price can indeed be used to improve the identification and estimation of the production function clearly remain to be investigated further, well beyond our simple, yet thorough, analysis here. ${ }^{22}$

\section{Concluding Remarks}

In their overview of the contribution of panel econometrics to the identification and estimation of production functions, Griliches and Mairesse (1998) emphasize the need to enhance our understanding of firms' behavior and of their sources of heterogeneity, as well as the need to improve and enrich the measurement of production and its factors. In particular, they point out how useful it would be to have information on firms' output prices, which is typically lacking. In this exercise, we have explored the impact of incorporating individual firm information on output prices and capacity utilization rates in panel-data estimates of production functions, taking advantage of the availability of such information for two similar samples of French and Spanish firms. Contrary to the conclusions which might be suggested by an a priori analysis, we find that, while the availability of information on firms' individual prices directly improves the measurement of production and productivity (and total factor productivity) at the firm level, it does not significantly affect the estimated elasticities of interest of the production

\footnotetext{
22 Jaumandreu and Mairesse (2005) is a preliminary paper which attempts to take some steps in this direction.
} 
function. This holds true regardless of whether we rely on the simplest OLS panel-data estimators or we use a battery of rather sophisticated IV estimation methods. The same, however, cannot be said for the use of information on capacity utilization rates, which acts as an important control, at least in most estimates. In any case, neither type of information can account for the wide disparities which are typically found when contrasting estimates relying mainly on the cross-sectional dimension of the data and on its time-series dimension (say, based on the levels of the variables or on their first differences).

These results are in a sense reassuring since they can validate the customary practice of simply deflating output measures (sales, value added etc.) by industry output price indices when estimating production functions. Yet, they are also disappointing with respect to the hopes of improving the implausible estimates of capital elasticities and returns to scale that are usually found in the time-series dimension of the data, when attempting to take care of the risks of heterogeneity and endogeneity biases. Our basic conclusion is thus that the failure to account for the dispersion of changes in individual prices probably has far fewer consequences than other specification errors, in particular those linked to errors in variables. Our findings are also somewhat disconcerting to the extent that they seem to imply great difficulty in distinguishing between the production function and the revenue function, and in estimating a satisfactory firm demand function.

Clearly, much remains to be done. First, the results need to be confirmed on different, larger samples, covering longer periods, with price measures based on different information sources, and preferably also for periods, countries and industries that have experienced significant inflation. Second, the estimates suggest that firm output prices and capacity utilization should be given a more explicit role in a model of the firm, by trying to take into account that price is a strategic variable in the competitive behavior of firms and that capacity utilization is an important factor of adjustment to the varying and uncertain condition of demand. This type of modeling can contribute to further improvement in the identification and estimation of production functions. Third, and this is the message on which we want to conclude, more effort should be devoted to developing the measurement of output prices at the firm and product level and to improving the accessibility of these price data for research purposes; this is the only way of opening up a wide field of studies on the behavior of firms and the functioning of markets.

\section{References}

Abbott, T. A. (1987), Producer Price Dispersion and the Analysis of Production, Ph.D. Dissertation, Harvard University.

Abbott, T. A. (1991), Producer Price Dispersion, Real Output and the Analysis of Production, Journal of Productivity Analysis 2, 179-195. 
Arellano, M. (2003), Panel Data Econometrics, Oxford University Press, Oxford.

Arellano, M. and Bond, S. (1991), Some Tests of Specification for Panel Data: Monte Carlo Evidence and an Application to Employment Equations, Review of Economic Studies 58, 277-297.

Arellano, M. and Bover, O. (1995), Another Look at the Instrumental-variable Estimation of Error-components Models, Journal of Econometrics 68, 29-52.

Arellano, M. and Honore, B. (2001), Panel Data Models: Some Recent Developments, in J. J. Heckman and E. Leamer (eds.), Handbook of Econometrics, Vol. 5, North-Holland, Amsterdam.

Blundell, R. and Bond, S. (2000), GMM Estimation with Persistent Panel Data: An Application to Production Functions, Econometric Reviews 19, 321-340.

Crépon, B. and Mairesse, J. (1996), The Chamberlain Approach: An Overview and some Simulation Experiments, in L. Matyas and P. Sevestre (eds.), The Econometrics of Panel Data: A Handbook of the Theory with Applications, 2nd ed., Chapter 14, Kluwer Academic Publishers, Dordrecht, 323-391.

Crépon, B., Desplatz, R. and Mairesse, J. (1999), Estimating Price-Cost Margins, Scale Economies and Workers' Bargaining Power at the Firm Level, CREST Working Paper no. G9917, Paris.

Griliches, Z. and Mairesse, J. (1984), Productivity and Research-Development at the Firm Level, in Z. Griliches (ed.), Research and Development, Patents and Productivity, University Press of Chicago, Chicago, 271-297.

Griliches, Z. and Mairesse, J. (1998), Production Function: The Search for Identification, in S. Strøm (ed.), The Ragnar Frisch Centennial Symposium, Cambridge University Press, Cambridge, 169-203.

Jaumandreu, J. and Mairesse, J. (2005), Using Price and Demand Information to Identify Production Functions, mimeo, ENSAE, Paris.

Klette, J. and Griliches, Z. (1996), The Inconsistency of Common Scale Estimators when Output Prices are Unobserved and Endogenous, Journal of Applied Econometrics 11, 343-361.

Mairesse, J. (1990), Time-series and Cross-sectional Estimates on Panel Data: Why Are They Different and Why Should They Be Equal?, in J. Hartog, G. Ridder and J. Theeuwes (eds.), Panel Data and Labor Market Studies, North-Holland, Amsterdam, 81-95.

Mairesse, J. and Desplatz, R. (2003), Econométrie de la production sur données de panel et dispersion des prix de production: quels biais d'estimation?, Revue d'Economie Politique 113 (6), 749-772.

Marschak, J. and Andrews, W. (1944), Random Simultaneous Equations and the Theory of Production, Econometrica 46, 49-85.

Melitz, M. (2000), Estimating Firm-level Productivity in Differentiated Product Industries, mimeo, Harvard University.

Øksendal, B. (1985), Stochastic Differential Equations. An Introduction with Applications, Springer-Verlag, Berlin.

Ornaghi, C. (2005), Assessing the Effects of Measurement Errors on the Estimation of Production Functions, forthcoming in Journal of Applied Econometrics.

Phelps-Brown, E. H. (1957), The Meaning of the Fitted Cobb-Douglas Functions, Quarterly Journal of Economics 71, 546-560. 